\title{
UTILIZAÇÃO DE SEMINÁRIOS COMO MEIO FACILITADOR NO PROCESSO DE ENSINO- APRENDIZAGEM DE QUÍMICA
}

*SOUSA, I. M. (IFRN; PINHEIRO, I. A. M. (IFRN); FERNANDES, E. M. (EEPAD); ALVES, L. A. (IFRN); BERTINI, L. M. (IFRN); FERNANDES, P. R. N. (IFRN)

\section{RESUMO}

A Química é uma disciplina que está diretamente ligada ao cotidiano dos alunos. No entanto, nem sempre é possível fazer essa relação em sala de aula dependendo da metodologia que está sendo utilizada. Propor a realização de seminários é uma alternativa bastante viável. Os alunos estudam o tema, pesquisam e formulam ideias, o que facilita o processo de ensino-aprendizagem. A partir deste contexto, o presente trabalho refere-se a utilização de seminários para iniciar o estudo de modelos atômicos na 1ạ série do Ensino Médio da Escola
Estadual Professor Antônio Dantas, no município de Apodi - RN. Os resultados do uso dos seminários foram satisfatórios, mostrando que eles podem contribuir de maneira positiva na aprendizagem dos alunos.

PALAVRAS-CHAVE: Química, seminários, modelos atômicos.

\section{SEMINARS USE AS TRAINER IN THE PROCESS OF LEARNING TEACHING CHEMISTRY}

Chemistry is a discipline that is directly linked to the daily lives of students. However it is not always possible to make this relationship in the classroom depending on the methodology that is being used. Propose seminars is a very viable alternative. Students study the topic, research and formulate ideas which facilitates the process of teaching and learning.
From this context, this work relates to the use of seminars to start the study models atômicos. Na 1st high school series Escola Estadual Professor Antônio Dantas, in the municipality of Apodi - RN. The results of the use of seminars were satisfactory, showing that they can contribute positively on student learning.

KEY-WORDS: Chemistry, seminars, atomic models. 


\section{UTILIZAÇÃO DE SEMINÁRIOS COMO MEIO FACILITADOR NO PROCESSO DE ENSINO- APRENDIZAGEM DE QUÍMICA}

\section{INTRODUÇÃO}

Apesar de a Química fazer parte do dia a dia dos alunos, nem sempre é fácil fazer com que eles percebam essa relação. Tudo, ou muito, vai depender das metodologias utilizadas em sala de aula pelos professores.

Atualmente, os docentes estão buscando formas de inverter esta situação. A realização de seminários é vista como uma boa alternativa para melhorar o contato do aluno com a química, pois com os seminários os alunos adquirem o conhecimento estudando e pesquisando, para em seguida formular ideias que facilitem sua aprendizagem.

A cada nova unidade, os conteúdos são retomados para que fiquem solidamente incorporados à estrutura cognitiva dos alunos, no sentido de auxiliar a busca de novas explicações (QUEIROZ, 2004).

O conteúdo de modelos atômicos exige muita leitura e atenção, o que muitas vezes não acontece nas aulas de Química. Trabalhos dedicados à análise da abordagem da estrutura atômica no ensino de química da escola básica têm mostrado sua inadequação e a necessidade de se elaborar novas metodologias para o seu ensino (EICHLER, 2000). Ao elaborar um seminário, o aluno se vê desafiado a expor o seu conhecimento, o que facilita a aprendizagem.

O professor de Química deve procurar atividades metodológicas que exercitem habilidades exigidas na sociedade. A autoconfiança e a aprendizagem, assim como a cooperação e o incentivo ao pensamento coletivo, são alcançados com o desenvolvimento de seminários (NESPOLI; 2010).

A partir da dificuldade encontrada pelos professores de Química em exercitar uma metodologia que facilite o processo de ensino aprendizagem do conteúdo de modelos atômicos, o presente trabalho teve como objetivo utilizar o seminário como ferramenta de ensino.

\section{MATERIAIS E MÉTODOS}

Uma semana antes da apresentação dos seminários, a sala, composta por 26 (vinte e seis) alunos, foi dividida em quatro equipes, sendo que cada equipe ficou com um tópico referente ao conteúdo de modelos atômicos para estudar e apresentar. Foram dadas orientações de como deveria ser apresentado o seminário. Os aspectos que seriam analisados estão listados abaixo:

$\checkmark$ Postura individual e do grupo;

$\checkmark$ Qualidade dos slides;

$\checkmark$ Domínio do conteúdo;

$\checkmark$ Respeito com os colegas;

$\checkmark$ Tempo estipulado em quinze minutos . 
Após a apresentação dos seminários, o professor de Química retomou o conteúdo abordado para que todos entendessem melhor. Para avaliar a atividade foi aplicado um questionário de aceitação e uma lista de exercícios.

\section{RESULTADOS E DISCUSSÕES}

Após a aplicação do questionário de aceitação da atividade, os dados obtidos foram organizados em porcentagem no gráfico 1, a seguir:

Grafico 1: Aceitação dos alunos à realização do seminário

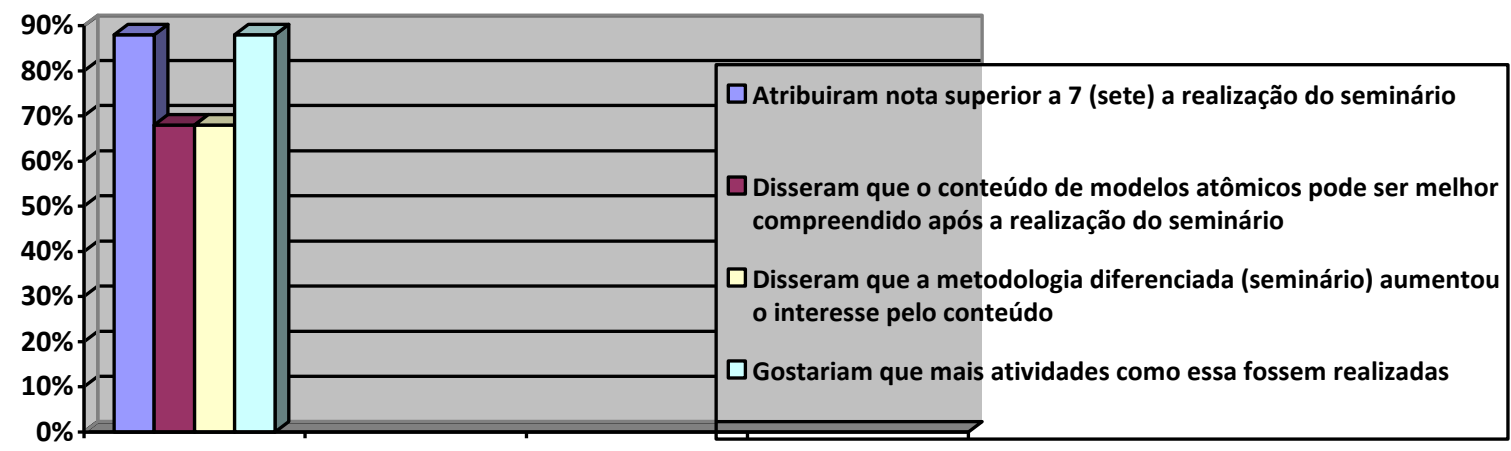

A porcentagem de erros e acertos do exercício aplicado na turma após o seminário está organizado no gráfico 2 , a seguir:

Gráfico 2: Erros e acertos dos alunos no exercício sobre modelos atômicos

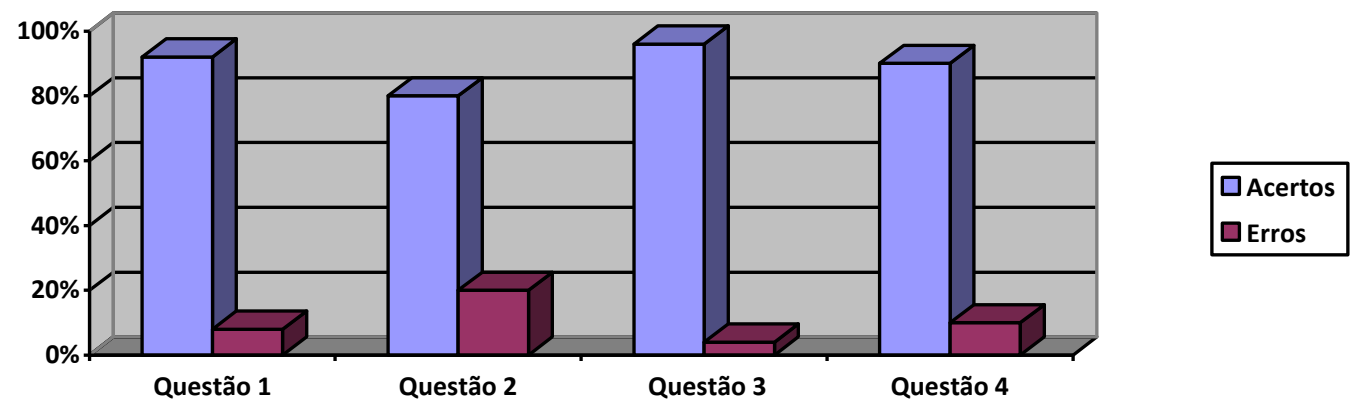

Percebe-se pela análise dos gráficos, que os seminários contribuíram na aprendizagem dos alunos, os quais afirmaram, em sua maioria, que o conteúdo foi melhor assimilado e que seu interesse pelo mesmo aumentou. Além disso, o desejo da realização de outros seminários mostra que essa metodologia foi bem recebida pelos alunos.

A satisfação dos alunos é refletida no gráfico 2, que apresenta uma margem de acerto do exercício, feito após o seminário, muito superior ao número de erros.

\section{CONCLUSÃO}

Os seminários podem contribuir efetivamente tanto para o processo de ensinoaprendizagem em Química como para o aumento do interesse dos alunos nas aulas. Foi notória a empolgação dos alunos na realização da atividade. 


\section{REFERÊNCIAS}

EICHLER, Marcelo; PINO, José Claudio del. COMPUTADORES EM EDUCAÇÃO QUÍMICA: ESTRUTURA ATÔMICA E TABELA PERIÓdICA. 2000. Disponível em: <http://quimicanova.sbq.org.br/imagebank/pdf/Vol23No6_835_18.pdf>. Acesso em: 06 jul. 2016. NESPOLI, André. SEMINÁRIO NO ENSINO DE QUÍMICA. 2010. Disponível em: <http://www.xveneq2010.unb.br/resumos/R0141-3.pdf>. Acesso em: 06 jul. 2016.

QUEIROZ, S. L. Do fazer ao compreender ciências: reflexões sobre o aprendizado de alunos de iniciação científica em química. Ciência \& Educação, Bauru, v. 10, n. 1, 2004. 